\title{
LXIV. Observations on Professor Plateau's defence of his theory of accidental colours
}

\author{
Sir David Brewster K.H. V.P.R.S. Ed.
}

To cite this article: Sir David Brewster K.H. V.P.R.S. Ed. (1839) LXIV. Observations on Professor Plateau's defence of his theory of accidental colours, Philosophical Magazine Series 3, 15:98, 435-441, DOI: $10.1080 / 14786443908649917$

To link to this article: http://dx.doi.org/10.1080/14786443908649917

册 Published online: 01 Jun 2009.

Submit your article to this journal

Џll Article views: 2

Q View related articles $₫$ 
Sir D. Brewster on the Theory of Accidental Colours. 435

squared differences, does not a natural passage to the former lie through $n$ functions of the squared differences?

In other words, may not the quantities $\Sigma \mathrm{SPD}\left(h_{1} h_{2} \ldots h_{n}\right)$, \&c., serve as natural and valuable intermediaries between the coefficients of an equation involving simple quantities and the coefficients of the equation involving the squares of their differences?

P.S. In the next part I trust to be able to present the readers of this Magazine with a direct and symmetrical method of eliminating any number of unknown quantities between any number of equations of any degree, by a newly invented process of symbolical multiplication, and the use of compound symbols of notation.

I must not omit to state that the constituents of multiplication $\lambda_{r}$ and $\mu_{r}$ explained in Cor. 2. to Theorem (3.) are equal to the expressions

$$
\Sigma\left(x-k_{1}\right)\left(x-k_{2}\right) \ldots\left(x-k_{m-r-1}\right) \frac{\left(\begin{array}{l}
k_{1} \cdot k_{2} \ldots k_{m-r-1} \\
-h_{1}-h_{2} \ldots .-h_{n}
\end{array}\right)}{\left(\begin{array}{c}
k_{1} \cdot k_{2} \ldots k_{m-r-1} \\
-k_{m-r} \ldots k_{m}
\end{array}\right)}
$$

and its analogue respectively.

University College, London, October 15, 1839.

[To be continued.]

LXIV. Observations on Professor PJatean's Defence of his Theory of accidental Colours. By Sir Davin Brewster, K.H., V.P.R.S. Ed.*

IN the Numbers of this Journal for May and June last, Professor Plateau has published an elaborate defence of his "Theory of accidental Colours," against certain observations which have been made upon it in England. The authors to whose observations he replies are an anonymous writer in the Edinburgh Review $\uparrow$ and myself; and as $I$ have no hesitation in acknowledging that $I$ am the anonymous reviewer, I feel myself bound to bear the whole burden of examining the able defence which Professor Plateau has now made. Having the honour of being personally acquainted with this distinguished individtal, and admiring his character as well as his talents, I regret that my opinion should have been placed in collision with his; but from the temperate and truly philosophical manner in which he luas conducted the discussion, and which in so far as the first of these qualities is concerned I shall not fail to imitate, I trust the interests of science and of

* Communicated by the Author.

+ April 1834, p. 160.

$2 \mathrm{~F}_{2}$ 


\section{Sir D. Brewster's Olseryations on Prof. Plateau's}

truth will not be compromised by a further analysis of those phænomena of our visual sensations respecting which these differences of opiniơn have arisen.

Although I have devoted much time to the study of the phrnomena of accidental colours, yet my observations have been made at distant intervals, and recorded from time to time without any design of establishing a particular theory. At one time I believed in the theory of the diminution of sensibility, till a series of specific observations led me to a new theory, which, as I shall afterwards show, differs very little, if it differ at all, from that of M. Platean in its leading aspect.

To this general theory M. Plateau has added two distinct propositions respecting the combination of accidental colours, and their law of succession; and it is on these points that I have the misfortune of differing with him in opinion.

On the first of these points M. Plateau maintains, that while "the combiration of real colours produces white, the combination of accidental colours produces the contrary to white, or black." That is, "whereas two real complementary colours produce together white, two accidental complementary colours produce together black*",

With respect to this proposition, I have stated in the Edinburgh Review, that we cannot, with any propriety of language, consider one accidental colour as added to, or combined roith another; that the proposition itself is a verbal illusion; and that the physical fact which it expresses has been long known to philosophers, and is indeed the necessary result of our previous knowledge on the subject.

After endeavouring to controvert this opinion, M. Platean does not conclude that it is erroneous; he concludes only, and he puts his conclusion in italics, that he has not merely expressed what has been long knowon. The ground upon which he rests this conclusion is, that $I$ did not seem to be aware that his proposition included the new fact, that accidental colours were seen in total obscurity. Now I admit the force of this exception, and I acknowledge that the visibility of accidental colours in the dark was not known to Buffon, Darwin, or Rumford; but this fact has no connexion with the proposition under discussion, any further than that it overturns the theory of sensibility, and weakens my argument in so far as it was supposed to depend upon that theory.

Now though I abandoned as incorrect, and have long ago abandoned, the theory of a diminution of sensibility as iurnishing the true explanation of the phænomena of accidental colours, I still maintain that a diminution of sensibility is a ne-

* Ann. de Chim., Aug. 1833, p. 388, and this Journal, vol. xiv. p. 334. 
cessary accompaniment of accidental colours; that is, that the portion of the retina which affords the accidental colour is more or less insensible to every other colour but that which it affords. 'To deny the influence of diminished sensibility as a cause, is a very different thing from denying it as an effect, and it is by confounding these two propositions that $M$. Plateau seems to me to have erred.

Now if we admit, what I think is capable of the most ri.. gorous proof, that there is a diminished sensibility of the part of the retina affected, it follows as a matter of course that the sum of those diminished sensibilities for all the rays of white light must be an insensibility to them all, that is blackness.

But why should we examine M. Plateau's proposition, by means of theories, or of opinions, that are in any way disputed or ambiguous? Is it not a demonstrated fact, admitted by every philosopher, that the accidental colour of white is black?"? that is, the sum of the actions of all the component colours of white light, when their action has ceased, or the combination of all their accidental colours, is blackness. If we take two complementary colours, namely the red and green tints forming the ordinary and extraordinary pencils in the polarized ring, which by overlapping form white light, then it is manifest that the accidental colour of the overlapping part is black, and hence the sum of the action of the red and green acting separately must also be black.

I have no hesitation, therefore, in averring that the view which I have taken in the Elinburgh Review and elsewhere of Prof. Plateau's proposition is in every respect correct.

In replying to the observations of Professor Plateau in defence of his theory of accidental colours, I feel a difficulty of a very peculiar kind. He admits that his theory is more firequently opposed by the results of experiment* than supported by them; and as this is the very opinion which I have maintained, it would seem almost unnecessary to continue the discussion. In case, however, I may have misapprehended that part of his reply in which this admission is made, it will be necessary to enter more minutely into the subject.

But before I do this, I must acknowledge a mistake which I have committed, and which he has pointed out, in ascribing to him the assertion, that the regular altcrnation of the PRIMITIVE and ACCIDENTAI colour, is the effect most frequently observed, whereas he has maintained the contrary proposition, that the effect which he most frequently observed was that of the DISAPPLARANCE and REAPPFARANCE of the negative or accidental inpression alone. In expressing my regret for this mistake, into wbich I was led by believing Professor Plateau's

- In this Journal, vol, xiv. p. 340. 


\section{Sir D. Brewster's Observations on Prof Plateau's.}

theory to have a better foundation than it has, I must call the reader's attention to the fact, that my mistake wos most unfavourable to my own argument; and that had I not made the oversight, I should have been able to overthrow Prof. Plateau's theory by means of his experiments as well as by my own.

This theory, as given in $§ 5$, of Prof. Plateau's Fssai d'une Théorie Générale, \&c. \&c., Brussels, 1834, is expressed in the following manner: "The retina returns to its primitive state by a series of decreasing oscillations like a spring or a pendulum; the primitive impression being rapidly effaced in order to be followed by an opposite effect, the nature of which will be determined by experiment; the primitive impression will then show itself again, but more feebly, and so on in succession, till the eye cannot distinguish the impressions any longer." The theory therefore is that the primitive and aCCiDENTAL colours follow each other in regular succession till they disappear altogether.

After an elaborate and able examination of the various phænomena of accidental colours, Prof. Plateau gives the following general result, which, though mixed with much hypothetical language, expresses clearly enough the experimental results at which he has arrived:-

"When the retina is submitted to the action of rays of any colour, it resists this action, and tends to resume its ordinary condition with a force more or less intense. If it is then suddenly withdrawn from the exciting cause, it returns to its ordinary condition by an oscillatory movement, the intensity of which is proportional to the duration of the previous action; a movement, in virtue of which the impression passes, at first, from the positive to the negative state, ihen continues generally to oscillate in a manner more or loss regular, while it becomes weaker and weaker. Sometimes it only disappears and reappcars alternatcly, and sometimes it passes successively from the NEGATIVE to the Positive state, and vice versa." is

Prof. Plateau goes on to state that the "agreement between the results of experiment and the second hypothesis (the hypothesis already given) is remarkable. If the oscillations of the impression which is effaced are generally incomplete or irregular, we must attribute it to causes which the actual state of this part of the science of vision does not yet permit us to appreciate."

Without taking advantage of the circumstances that Prof. Plateau does not here acknowledge, as he does in the Annales de Chimiet, that the appearance and disappearance of the accidental colour is the fact most frequently observed, the admission,

$$
\text { * Essai, \&c. p. } 64 \text {. August,1833, p. } 39
$$


that even the oscillations, when they do occur, are generally incomplete or irregular, is a complete proof that the theory is not supported by experiment; nay, results directly opposite to the theory are acknowledged to be more frequent than results agreeing with it, and these last are admitted to be generally incomplete or irregular.

Now, Prof. Plateau admits, that the most frequent result, namely, the disappearance and reappearance of the accidental colour, was observed by many authors, and particularly by Scherffer and Darwin. This is perfectly true, and indeed I cannot conceive how any person could have studied the subject experimentally without observing it. With regard to the rarer phænomenon which Prof. Plateau and Prof. Quetelet have each seen, and which represents the theory, I have frequently observed the one colour succeed the other, but never the whole phænomenon; and since I have read Prof. Plateau's writings, I have endeavoured in vain to see it.

Here then we have two classes of facts; one of which, viz. the rarer class, leads to one theory, and the other, viz. the more common class, leads to another theory; and Prof. Plateau adopts the theory least supported by facts, solely, we presume, because it appears more beautiful, and more consistent with analogy.

Regarding the subject as not ripe for generalization, I have ventured to explain the phænomena of the disappearances and reappearances of the accidental colour, and the occasional succession of the negative and positive impressions, by the operation of certain disturbing causes, which must undoubtedly exercise an influence over all such phænomena. Prof. Platean answers these arguments by stating, that if such causes had presented themselves, " he must have been a very unskilful observer not to have noticed their influence, nor have secured himself against them." But ouservers not very unskilful have actually found that the accidental colour may be obliterated temporarily or permanently by involuntarily winking, or by closing the eyes with different degrees of pressure, or by distending the eyes, or by knocking the head; and we believe that the results of all such experiments are affected even by the position of the head, the indirect action of light, the state of the stomach, and the pressure of the blood-vessels on the eye-balls.

Before concluding these observations, I must beg leave to correct a mistake, no doubt accidentally made by Prof. Plateau in comparing my theory of accidental colours with his own. "In a certain point of view, as may be seen, Sir David Brewster's theory and mine approach each other; and indeed, 


\section{Sir D. Brewster on the Theory of Accidental Colours.}

in the first place, they have that in common, that they consider the accidental colour as owing to an impression of a peculiar nature which is spontaneonsly generated in the organs, and not as the result of a relative insensibility to certain rays. On the other hand, according to Sir David Brewster, the accidental colour unfolds itself on the retina during the contemplation of the direct colour, and combines itself with this latter; and according to me, the opposite effort of the retina, whence results the negative sensation, as soon as that effort ceases to be counteracted, likewise unfolds itself during the contemplation of the direct colour, and combines itself, in some respect, with this latter, neutralizing it partially. But only Sir David Brewster maintains that the combination of the two sensations produces whitteness, whereas I have shown that upon an object insulated from every lateral influence the result is on the contrary blackness*."

Now it is not the case, that I maintain "that the combination of the two sensations produces whiteness." My words are: "The effect of this vision of the green (the accidental colour seen when looking at a red seal,) is to make the RED appear much paler by its admixture with it. The red and green tend to produce whiteness; but as the direct red greatly predominates over the accidental green, the result is alrcays pale red." Now as the original seal was a bright red, and as I maintain that the physiological result is a pale red, why does Prof. Plateau allege that I make the combination of the two sensations produce rohiteness? Does not he himself maintain the same opinion which I have above expressed, when he sayst, "that the combination of the two actions" is a gradual falling off in the apparent brightness of the object looked at? No observer can doubt the correctness of my opinion, or rather of the fact which I observed.

Upon the supposition that his theory of negative and positive oscillations is an incontrovertible law of our visual sensations, M. Plateau, like all theorists who are not satisfied with the plain results of experiment, extends it to all the other senses, when their respective organs, caused to deviate from their ordinary condition, are suddenly withdrawn from the exciting cause. They return, he conceives, to their ordinary condition by an oscillatory movement, which produces negative impressions. He endeavours, without any success, to apply this principle to certain phænomena of sound and tcuch, and even taste $f$; and, pushing his thenry to the very verge of sobriety, he asks, "if it is not probable that the principle of oscillatory

* See this Journal, vol. xiv. p. 443.

+ Ibid. p. 442, botton.

$\ddagger$ He considers the arricre gont, or back taste, as the negative cscillation! 
movements may be extended to phænomena of the most elevated order, to facts purely moral? Who does not know, for example, that the liveliest joy is often followed by a sentiment of sadness, which, gradually decaying, is again followed by agreeable recollections, which are themselves finally effaced? Have we not here oscillations decreasing from pleasure to pain, from pain to pleasure; and from pleasure to the normal state of the mind?" Our ingenious author employs the same principle to explain the effects of moral contrast; but we shall pursue the subject no further, lest we should be accused of prejudicing our readers against our author's optics, by dwelling upon the singularities of his metaphysics. We must warn our young readers, however, against being led away from the path of sober inquiry by the pursuit of such ingenious analogies. It may be amusing to fanciful minds, for it certainly is poetical, to regard pleasure and pain, joys and sorrows, as the lights and shadores of our being,- -as the positive and negative tints which colour in succession the livid perspective of life; but the principle, if once encouraged, would soon be pushed to a more hazardous extent, and the ever-varying phases of our moral nature would soon be represented by the abscisses and ordinates of a mathematical curve.

St. Leonard's, St. Andrews, Nov. 12, 1839.

LXV. Observations of Shooting Stars on the nights of the 10th and 11 th of August, 1839. By R. M. Z.*

To the Editors of the Philosophical Magazine and Journal.

Gentiemen,

A REQUEST having been made that any notice relative to the August periodical shooting stars should be communicated to the Philosophical Magazine, I have transmitted the following observations made by me on the 10th and 11 th of August inst. Brief and imperfect though these observations may be, yet perhaps, as facts bearing upon a hitherto little explored subject, they may not be wholly devoid of interest.

I must be permitted to premise, that my observations were confined to a limited portion of the heavens, the aspect of $\mathrm{my}$ apartment being N.N.W. and that $I$ was without an assistant. On the night of the loth I was prevented from commencing any observations until twenty minutes past eleven, and at thirty minutes past twelve the sky became overcast, and the observations were discontinued. During this time (with,

* On the subject of this communication, see our last Number, p. 372. -Evit. 